\title{
A clinical study on peripartum cardiomyopathy at tertiary care hospital
}

\author{
Seeta S. Garag, Vinay Raju D.*
}

Department of Obstetrics and Gynecology, KIMS Hubali, Karnataka, India

Received: 22 September 2019

Accepted: 25 October 2019

\author{
*Correspondence: \\ Dr. Vinay Raju D., \\ E-mail: vinayraju319@gmail.com
}

Copyright: (c) the author(s), publisher and licensee Medip Academy. This is an open-access article distributed under the terms of the Creative Commons Attribution Non-Commercial License, which permits unrestricted non-commercial use, distribution, and reproduction in any medium, provided the original work is properly cited.

\begin{abstract}
Background: Cardiac diseases complicate 1-4\% of pregnancies in women without pre-existing cardiac abnormalities. Cardiac disease in the pregnant woman can present a challenge to the obstetrician, cardiologist and neonatologist. Peripartum cardiomyopathy (PPCM) is an idiopathic disorder defined as heart failure occurring in women during the last month of pregnancy and up to 5 months postpartum. Aim is to study the burden of the disease, maternal outcome in PPCM.

Methods: The present study was conducted among the antenatal women admitted in the department of Obstetrics and Gynecology at KIMS, Hubli with a previously diagnosed cardiac disease or diagnosed after admission during index pregnancy from December 2016 to May 2018. The mothers were followed up till discharge. Maternal outcome was noted as discharged or died.

Results: A total of 11 cases of PPCM noted in our study out of which one case was developed before delivery, and 10 cases developed postnatally. Out of ten cases which were developed postnatally, 5 patients died giving around $50 \%$ of mortality rate.

Conclusions: PPCM affects previously normal healthy women in the last month of pregnancy and up to 5 months after delivery. Careful assessment of risk factors contributing PPCM could help in their prevention. And these patients should be stratified in developing PPCM in future pregnancies through proper tools available.
\end{abstract}

Keywords: Anemia, Cardiac diseases, Echocardiography, Maternal mortality, Peripartum cardiomyopathy, Pregnancy-induced hypertension

\section{INTRODUCTION}

Pregnancy makes a significant demand on the cardiovascular system. About $15-52 \%$ of cardiac abnormalities are first diagnosed during routine antenatal examination or because of symptoms brought about by the physiological changes of pregnancy. The marked pregnancy induced anatomical and functional changes in cardiac physiology can have a profound effect on the underlying heart disease. The prevalence of previously undiagnosed maternal cardiac structural abnormalities is significantly increased in women with high mid-trimester uterine artery doppler resistance indices. ${ }^{1}$
The major cardiac causes in the latest triennium of the Centre for Maternal and Child Enquiries (CMACE)'s confidential enquiry into maternal death include myocardial infraction, dissection of thoracic aorta, and peripartum cardiomyopathy. Despite the potential for significant maternal morbidity, most patients with cardiac disease can expect a satisfactory outcome with careful antenatal, intrapartum and post-partum management. The rate of complications is related to several factors, including maternal functional status, myocardial dysfunction, significant aortic or mitral valve stenosis and history of arrhythmias or a cardiac event. ${ }^{2}$ 
The reported incidence of PPCM varies because the diagnosis is not always consistent and a comparison with age-matched nonpregnant women does not exist. ${ }^{3-5}$

\section{Diagnostic criteria for peripartum cardiomyopathy}

All 4 of the following:

\section{Classic}

- Development of cardiac failure in the last month of pregnancy or within 5 months postpartum

- No identifiable cause for the cardiac failure

- No recognizable heart disease before the last month of pregnancy.

\section{Additional}

- Strict echocardiographic indication of left ventricular dysfunction:
a. Ejection fraction $<45 \%$ and/or
b. Fractional shortening $<30 \%$
c. End-diastolic dimension $>2.7 \mathrm{~cm} / \mathrm{m}^{2}$.

\section{Objectives of this study were}

- To know the burden of PPCM complicating pregnancy in our hospital

- To record the maternal complications.

\section{METHODS}

\section{Source of data and materials}

The present study was a Prospective observational study conducted among the antenatal women admitted in the department of obstetrics and gynecology, at KIMS, Hubli with a previously diagnosed cardiac disease or diagnosed after admission during index pregnancy from December 2016 to May 2018.

\section{Inclusion criteria}

- All women admitted to the antenatal ward and labour room with diagnosis of PPCM in the last month of pregnancy

- Women developing cardiac complications during puerperium.

\section{Exclusion criteria}

- Patients with cardiac disease receiving outpatient care.

Present study is a prospective observational study. considering inclusion and exclusion criteria, selected patients were counselled regarding the study. After obtaining valid consent, a pre-designed proforma was used. Detailed clinical history regarding the no of pregnancies, presence of cardiac illness, symptoms, treatment received was noted. Necessary obstetrical examination was done. Laboratory investigations. Electrocardiography and echocardiography were done in all the patients and the diagnosis was confirmed. The mothers were followed up till discharge. Maternal outcome was noted as discharged or died.

\section{Statistical analysis}

All the collected data variables were entered into an excel sheet and after appropriate data filtration, the data sheet was transferred to and analysed using SPSS software version 22. Appropriate descriptive statistics were used to describe the data and appropriate tests of significance were applied to find out the associations between the variables

\section{RESULTS}

A total of 11 cases of PPCM noted in our study during a period of one and half years, out of which one case was developed before delivery, and 10 cases developed postnatally. Out of ten cases which were developed postnatally, 5 patients died giving around $50 \%$ of mortality rate among peripartum cardiomyopathy, shows how serious the disease is (Figure 1).

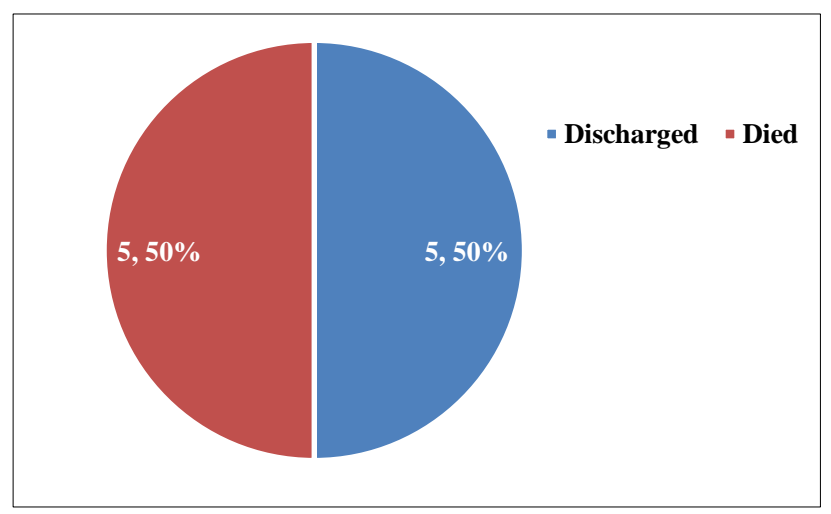

Figure 1: Outcome among patients with peripartum cardiomyopathy.

\section{DISCUSSION}

In our study there is comparatively higher mortality rate among peripartum cardiomyopathy cases, reasons may be, precipitating factors like anemia, PIH etc.

Even though peripartum cardiomyopathy is a rare but serious condition of unknown cause. Mortality rate in peripartum cardiomyopathy ranging from $7 \%$ to $50 \%$. 9,10 Diagnosis of peripartum cardiomyopathy requires high awareness, and high degree of suspicion. Management of peripartum cardiomyopathy must be a multidisciplinary approach and should aim at improving heart failure symptoms first, thus the mortality rate due to peripartum cardiomyopathy can be decreased (Table 1$).{ }^{11}$ 
Table 1: Comparison of maternal outcome in peripartum cardiomyopathy among various studies.

\begin{tabular}{|c|c|c|}
\hline Study & $\begin{array}{l}\text { No of cases of } \\
\text { peripartum } \\
\text { cardiomyopathy }\end{array}$ & $\begin{array}{l}\text { Percentage } \\
\text { of } \\
\text { mortality }\end{array}$ \\
\hline Karamitsos TD et $\mathrm{al}^{6}$ & 39 & 26 \\
\hline Goland S et $\mathrm{al}^{7}$ & 44 & 15.9 \\
\hline Silwa $\mathrm{K}$ et $\mathrm{al}^{8}$ & 29 & 32 \\
\hline Our study & 10 & 50 \\
\hline
\end{tabular}

\section{CONCLUSION}

The PPCM affects normal healthy women in last month of pregnancy and up to five months of puerperium. In some women the disease worsens rapidly and death may occur. Since PPCM has multifactorial in origin exact pathogenesis is not able to explain in all women. Women survived from PPCM may recover completely. Sometimes they are at risk for the heart failure and PPCM in the subsequent pregnancies.

Funding: No funding sources Conflict of interest: None declared

Ethical approval: The study was approved by the Institutional Ethics Committee

\section{REFERENCES}

1. Cunnigham FC, Leveno KJ, Bloom SJ, Hauth JC, Rouse DJ, Spong CY. Williams: obstetrics $24^{\text {th }}$ edn. United States McGraw-Hill medical publishing division; 2014:973-1000.

2. Tomlinson MW. Chapter 36 Cardiac Disease: Editor: David K. James; High risk pregnancy: management options $4^{\text {th }}$ ed; 2006; ISBN 978-1-4160-5908-0.

3. Pearson GD, Veille JC, Rahimtoola S, Hsia J, Oakley CM, Hosenpud JD, et al. Peripartum cardiomyopathy: national heart, lung, and blood institute and office of rare diseases (National Institutes of Health) workshop recommendations and review. JAMA. 2000;283(9):1183-8.

4. Sliwa K, Fett J, Elkayam U. Peripartum cardiomyopathy. Lancet. 2006;368(9536):687-69.

5. James P. A review of peripartum cardiomyopathy. Int J Clin Pract. 2004;58(4):363-5.

6. Karamitsos TD, Neubauer S. Detecting diffuse myocardial fibrosis with CMR: the future has only just begun. Cardiovascular Imaging; JACC. 2013;6(6):684-6.

7. Goland S, Modi K, Bitar F, Janmohamed M, Mirocha JM, Czer LSC, et al. Clinical profile and predictors of complications in peripartum cardiomyopathy. J Card Fail. 2009;15(8):645-50.

8. Sliwa K, Hilfiker-Kleiner D, Petrie MC. Current state of knowledge on aetiology, diagnosis, management, and therapy of peripartum cardiomyopathy: a position statement from the Heart Failure Association of the European Society of Cardiology Working Group on peripartum cardiomyopathy. Eu J Heart Fail. 2010;12(8):767-78.

9. Sovndal S, Tabas JA. Cardiovascular disorders in pregnancy. In: Pearlman MD, Tintinalli JE, Dyne PL, editors. Obstetric and Gynecologic Emergencies: Diagnosis and Management. 1st ed. New York: McGraw-Hill Medical Publishing Division; 2004:300-309.

10. Tidswell M. Peripartum cardiomyopathy. Crit Care Clin. 2004;20:777-88.

11. Bhattacharyya A, Basra SS, Sen P, Kar B. Peripartum cardiomyopathy: a review. Tex Heart Inst J. 2012;39(1):8-16.

Cite this article as: Garag SS, Raju DV. A clinical study on peripartum cardiomyopathy at tertiary care hospital. Int J Reprod Contracept Obstet Gynecol 2019;8:4780-2. 